\title{
Editorial
}

\section{Interpretando un proceso complejo: el ciclo de gobiernos del kirchnerismo en la Argentina}

DOI: $10.22395 /$ seec.v2 $\ln 47$ al

El inicio del reciente siglo encontró en América Latina la formación de un escenario de respuesta a los proyectos neoliberales, difundidos fuertemente durante el periodo en que dominaron las estrategias económicas e institucionales asociadas al Consenso de Washington. Desde entonces, bajo lo que algunos denominaron la "marea rosa" (Pink Tide), un conjunto de gobiernos de la región convergió en reinstalar la idea de impulsar proyectos inspirados en una mayor autonomía nacional y, para ello, en el fortalecimiento de los mercados internos y una renovada intervención estatal, apelando en muchos casos a procesos de renacionalización y, en prácticamente todos, a políticas de redistribución del ingreso a través del gasto público. Para el año 2010, Argentina, Bolivia, Brasil, Chile, Ecuador, Honduras, Nicaragua, Paraguay, Uruguay y Venezuela presentaban gobiernos que, más allá de la especifi cidad de sus experiencias, compartían estas características.

Inserto en este contexto, el ciclo reciente de gobiernos kirchneristas en Argentina (2003-2015) ha suscitado y suscita un sinfín de controversias académicas y en muchos otros ámbitos de la vida social. Ello, en gran medida, por cuanto se trató de un proceso sumamente complejo por múltiples razones, entre las que nos interesa resaltar cuatro.

- El kirchnerismo es hijo de una de las crisis más profundas, regresivas y multidimensionales que experimentó el país en su historia y, en ese marco, parte de los logros que experimentaron algunas variables socioeconómicas relevantes tuvo que ver precisamente con la salida de ese contexto, por demás crítico.

- Al igual que otras experiencias latinoamericanas, se trató de un momento histó rico marcado por ciertas rupturas importantes en los criterios ordenadores de la intervención estatal respecto de la fase neoliberal. Pero también, por acción u omisión, por la recuperación de algunos postulados propios de la tradición de la economía clásica.

- En un contexto internacional pujante durante varios años (con términos de intercambio favorables) se desplegó, en el plano interno, un conjunto de procesos 
novedosos, dada la historia previa: la vigencia de los superávits gemelos (fiscal y externo); el llamado "desendeudamiento"; un crecimiento económico considerable bajo el liderazgo de sectores productivos; y la creación de puestos de trabajo y el logro de mejoras no despreciables en materia de distribución del ingreso (en los dos últimos casos, a instancias del piso bajísimo dejado por las formas que asumió la resolución de la debacle del régimen de convertibilidad).

- A pesar de las rupturas existentes, también se pueden reconocer muchas líneas de continuidad con el neoliberalismo, entre las que sobresalen: la consolidación de un perfil de especialización y de inserción internacional, anclado mayormente en sectores procesadores de materias primas; el predominio del capital extranjero y de todo un entramado normativo funcional a su operatoria en el medio doméstico -legislación de inversión extranjera, tratados bilaterales de inversión, etc.-; la fuga de capitales locales al exterior; y el afianzamiento de la problemática de la dependencia tecnológica y de la heterogeneidad estructural característica del sector industrial.

Entre fines de la década pasada y principios de la actual, estos elementos de continuidad se articularon con otros que se gestaron en la etapa analizada en esta edición (fundamentalmente la crisis energética) y, además, con un viraje marcado en el escenario global. Así, se sentaron las bases para el inicio de una fase distinta de la economía argentina. Al finalizar el segundo mandato presidencial de Cristina Fernández de Kirchner, el país venía de alternar años de bajo crecimiento con otros de estancamiento y caída en el nivel de actividad (en un cuadro de redefinición de los liderazgos sectoriales); y a la inversa de los primeros años de gestión, la economía presentaba varios desequilibrios macroeconómicos (restricción externa, desequilibrio fiscal, inflación elevada), así como una disminución considerable en lo que refiere a la creación de empleos y la capacidad de recomposición de los salarios, con las consecuentes tensiones distributivas. Al mismo tiempo, se asistía a una renovada presencia e incidencia del capital financiero.

En ese contexto económico adverso, agravado a su vez por una confrontación cada vez más abierta del kirchnerismo con ciertos segmentos del capital concentrado (muchos de los cuales venían de internalizar ganancias elevadísimas y de reforzar con creces su centralidad estructural), el gobierno procuró dilatar el ajuste. Conforme este se tornó inevitable, en el marco de políticas aceptables por la coalición gobernante, se buscó conciliarlo con algunas compensaciones a las clases subalternas afectadas por esa misma medida. De conjunto, esto impuso un escenario de contradicciones crecientes en los resultados e, incluso, en las propias políticas públicas. 
La descripción previa evidencia la gran complejidad de la experiencia kirchnerista en Argentina. Sin embargo, en los hechos es habitual que esa complejidad quede relegada del análisis a merced de ideas como las de "década ganada" o "década perdida", con las que los defensores y los detractores del kirchnerismo suelen caracterizar al periodo, en los dos casos a partir de miradas muy sesgadas y con escasos fundamentos.

\section{SOBRE EL CONTENIDO DE ESTA EDICIÓN}

Para tratar de salir de esa grieta analítica y de aportar evidencias sólidas para pensar al kirchnerismo como lo que realmente fue (un proceso plagado de rupturas y continuidades, de contradicciones y conflictos), en lo que sigue el lector podrá encontrar un conjunto de trabajos que lo abordan desde diferentes aristas. Pese a la diversidad de temáticas tratadas, resulta posible identificar un denominador común para todos los estudios: el intento de aprehender la singularidad histórica del kirchnerismo desde un enfoque que abreva en el campo de la economía política.

En el primero de los artículos, Pablo Chena, Demián Panigo, Pablo Wahren y Leandro Bona analizan las diversas etapas por las que atravesó la economía argentina entre 2003 y 2015, así como la cambiante orientación de las políticas económicas. Asimismo, con un enfoque similar, el carácter de la intervención estatal, el trabajo de Alcides Bazza y Víctor Ramiro Fernández problematiza la naturaleza y los principales resultados de las políticas de fomento productivo-industrial y las de alcance regional.

Desde abordajes diferentes, pero que se complementan entre sí, la inserción internacional de Argentina conforma el eje de las indagaciones de Andrés Wainer (que busca identificar los factores estructurales más relevantes que concurrieron a explicar el paso de una situación de holgura a otra de restricción externa), Martín Abeles, Pablo Lavarello y Haroldo Montagú (la restricción externa desde la perspectiva de las brechas tecnológicas), y Pablo Nemiña (la política financiera externa desplegada por el gobierno y la relación establecida con el Fondo Monetario Internacional).

Por su parte, la contribución de Silvia Gorenstein, Jorge Hernández y Delia de la Torre se adentra en el estudio del desarrollo de dos sectores económicos clave, dada la matriz de especialización y las modalidades de inserción internacional que se afianzaron en tiempos del kirchnerismo: la producción de soja y derivados y la minería metalífera.

En estrecha relación con las investigaciones reseñadas hasta aquí, en la de Lorenzo Cassini, Gustavo García Zanotti y Martín Schorr se analiza la dinámica 
estructural de la cúpula empresaria local (las 200 firmas de mayores dimensiones del país) y la forma en la que impactaron a niveles macro y mesoeconómico las estrategias de acumulación llevadas a cabo por las diferentes fracciones que conviven al interior del poder económico doméstico. Finalmente, Agustín Arakaki, Juan Graña, Damián Kennedy y Matías Sánchez realizan un diagnóstico de la trayectoria del mercado de trabajo en el transcurso del período kirchnerista a partir de diferentes variables laborales y de ingresos. La principal conclusión es que, si bien se creó mucho empleo (básicamente en los primeros años), la población trabajadora cerró la etapa atravesada por una diferenciación en sus condiciones de reproducción más profundas que las existentes en el pasado.

Sin pretender una unidad discursiva o metodológica, sino justamente reconociendo las especificidades analíticas dentro del amplio espectro de la economía política heterodoxa, el conjunto de trabajos que integran esta edición puede ser analizado como un abordaje que, centrado en el complejo proceso que tuvo lugar en la Argentina reciente, puede contribuir a estimular otros emprendimientos académicos, abocados a considerar otras experiencias nacionales que forman el cambiante y siempre desafiante escenario latinoamericano.

Martín Schorr y Víctor Ramiro Fernández Editores invitados 